\title{
Congenital Heart Disease and Pulmonary Hypertension
}

Vedant Gupta, MD ${ }^{a, b}$, Adriano R. Tonelli, MDc, Richard A. Krasuski, MD ${ }^{d, *}$

\section{KEYWORDS}

- Congenital heart disease $\bullet$ Pulmonary hypertension • Eisenmenger syndrome $\bullet$ Management

- Treatment

\section{KEY POINTS}

- Pulmonary hypertension is common in patients with congenital heart disease, even in those patients with previously repaired lesions, and can lead to considerable symptoms, including exertional dyspnea.

- Pulmonary hypertension in these patients can be caused by pulmonary arterial or pulmonary venous causes and requires heart catheterization for accurate diagnosis.

- Some patients may be able to be treated with catheter-based or surgical interventions, particularly when the disease is reversible.

- Some patients with pulmonary arterial hypertension with unrepaired shunt lesions progress to Eisenmenger syndrome (pulmonary vascular disease with reversed [pulmonary-to-systemic] shunting). These patients have severe functional limitation and complications from systemic cyanosis.

- Successful treatment with each therapeutic class of selective pulmonary hypertension therapy (endothelin antagonists, phosphodiesterase-5 inhibitors and prostacyclin analogues) has been reported, although the BREATHE-5 (Bosentan Randomized Trial of Endothelin Antagonist Therapy-5) study, using bosentan, remains the only randomized trial of selective therapy in Eisenmenger syndrome.

- Prevention of pulmonary hypertension through early identification and repair of congenital heart defects is the ideal patient management.

\section{INTRODUCTION}

In 1897, Victor Eisenmenger described a patient with dyspnea since infancy who died of massive hemoptysis and was found on autopsy to have a large ventricular septal defect associated with abnormal pulmonary vasculature. This finding was not further characterized until nearly 60 years later. In the 1950s, more investigation gave further insight into the effect of congenital heart disease (CHD) on the pulmonary vasculature, and in 1958 Dr Paul Wood coined the term Eisenmenger syndrome to characterize patients with pulmonary hypertension $(\mathrm{PH})$ caused by high pulmonary vascular resistance (PVR) associated with a large ventricular septal defect. ${ }^{1}$ Multiple studies have

Disclosure: Dr Krasuski is on the speaker's bureau of Actelion Pharmaceuticals and Roche and has served as a consultant for Actelion Pharmaceuticals and Gilead. The other authors have no conflicts to disclose.

Funding support: None.

a Department of Internal Medicine, The Cleveland Clinic, 9500 Euclid Avenue, Cleveland, OH 44195, USA;

b Department of Medicine, The Cleveland Clinic, 9500 Euclid Avenue, Cleveland, OH 44195, USA; ' Department of Pulmonary and Critical Care, Respiratory Institute, A90 Cleveland Clinic, 9500 Euclid Avenue, Cleveland, $\mathrm{OH}$ 44195, USA; ${ }^{d}$ Department of Cardiovascular Medicine, Heart and Vascular Institute, The Cleveland Clinic, J2-4, 9500 Euclid Avenue, Cleveland, OH, USA

* Corresponding author.

E-mail address: krasusr@ccf.org 
since expanded our understanding of the syndrome to include other congenital heart defects. ${ }^{2-19} \mathrm{CHD}$ is one of the world's leading birth defects and pulmonary arterial hypertension (PAH) associated with $\mathrm{CHD}$ is one of the most common causes of morbidity and mortality in this group of patients. $^{20}$

\section{DEFINITION AND CLASSIFICATION}

$\mathrm{PH}$ was most recently defined by the Fourth World Symposium on Pulmonary Hypertension as a mean pulmonary arterial pressure of $25 \mathrm{~mm} \mathrm{Hg}$ or greater. ${ }^{21} \mathrm{PAH}$ is usually defined as the following: (1) mean pulmonary artery pressure of $25 \mathrm{~mm} \mathrm{Hg}$ or greater and (2) either pulmonary capillary wedge pressure (PCWP) of $15 \mathrm{~mm} \mathrm{Hg}$ or less or left ventricular end-diastolic pressure (LVEDP) of $15 \mathrm{~mm} \mathrm{Hg}$ or less or measured left atrial pressure of less than $15 \mathrm{~mm} \mathrm{Hg}$ and (3) PVR of 3 Wood units or greater. ${ }^{22}$ It is inherent from these definitions that right heart catheterization is an essential test for the diagnosis of PAH.

The Fourth World Symposium on Pulmonary Hypertension in Dana Point, California, revised the classification of PH in 2008 (Box 1). ${ }^{23} \mathrm{PH}$ is classified into 5 different groups. The importance of the clinical system, as well as allowing a better understanding of pathophysiology, is to give a framework for understanding important branch points in the management and treatment of different conditions known to cause PH. Diseases that are predominantly associated with $\mathrm{PAH}$ are clustered in group 1 , including idiopathic, heritable, drug-induced and toxin-induced and PAH associated with other conditions such as CHDs. ${ }^{23}$ The reason for including CHDs in group 1 is because its histology and endothelial cell abnormalities are indistinguishable from other causes of $\mathrm{PAH} .{ }^{24}$

Classically, all congenital conditions are grouped together when considered as a cause of PAH. However, it is important to identify the underlying congenital defect, because this has important prognostic implications. To help in this task, the Fourth World Symposium on Pulmonary Hypertension updated the anatomic and pathophysiologic classification of CHDs. This classification encompasses the type and dimension of the defect, direction of the shunt, associated cardiac and extracardiac abnormalities and repair status (Box 2). ${ }^{23}$ Its use is helpful in providing a more detailed description for each particular condition.

$\mathrm{PAH}$ associated with $\mathrm{CHD}$ (PAH-CHD) is generally classified as PAH associated with small defects (ventricular or atrial septal defects less than 1 and $2 \mathrm{~cm}$, respectively; presenting in similar fashion to idiopathic PAH), PAH associated with systemic-to-pulmonary shunts (moderate to large defects without cyanosis), Eisenmenger syndrome (large defects with severe increases in PVR and reversed or bidirectional shunting) and $\mathrm{PAH}$ after corrective surgery (PAH persists or recurs after surgery in the absence of postoperative residual lesions). ${ }^{23}$

Not all CHDs with systemic-to-pulmonary shunts lead to significant PH. Truncus arteriosus, ventricular septal defects, atrial septal defects, and patent ductus arteriosus are the mostly commonly identified lesions associated with severe $\mathrm{PH}$ and the development of Eisenmenger syndrome.

Eisenmenger syndrome is generally the result of systemic-to-pulmonary shunts caused by large congenital heart defects that with time lead to reversed (pulmonary-to-systemic) or bidirectional shunting accompanied by oxygen-unresponsive hypoxemia. It represents the most advanced form of PAH-CHD. This syndrome manifests as a disease process and not as an isolated condition. The clinical scenario includes reduced functional capacity, worsening hypoxia, cyanosis, erythrocytosis, and multiple organ system involvement.

\section{UNIQUE CHARACTERISTICS COMPARED WITH OTHER CAUSES OF PAH}

Although $\mathrm{PAH}-\mathrm{CHD}$ is similar in many ways to other causes of $\mathrm{PAH}$, there are some important differences. Unlike other causes of $\mathrm{PAH}$, congenital left-to-right shunts lead to a more progressive increase of right ventricular pressures early in life, allowing the right ventricle to remodel and accommodate for the increased afterload. This chronic course allows patients to reset their normal level of activity, adjusting it to help compensate for the chronic hypoxia. ${ }^{25-29}$ Therefore, they may not report the presence of significant symptoms with regular activity, underscoring the need for more objective assessment, as outlined later.

In addition, patients with $\mathrm{PAH}-\mathrm{CHD}$ more commonly experience hemoptysis, cerebrovascular accidents, brain abscesses, erythrocytosis, coagulation abnormalities, and cardiac arrhythmias than other causes of PAH. ${ }^{30}$ Adult patients with Eisenmenger syndrome have a more favorable hemodynamic profile and possibly a better prognosis than other groups of patients with $\mathrm{PAH} .{ }^{19}$

\section{EPIDEMIOLOGY}

Congenital heart defects are usually reported in $\sim 8$ of 1000 live births. ${ }^{31}$ Although the prevalence of CHD in the Western world has remained fairly constant, the number of adults with congenital heart lesions has gradually increased, as a result 
Box 1

Updated clinical classification of PH (Dana Point, 2008)

1. $\mathrm{PAH}$

1.1. Idiopathic PAH

1.2. Heritable

1.2.1. BMPR2

1.2.2. ALK1, endoglin (with or without hereditary hemorrhagic telangiectasia)

1.2.3. Unknown

1.3. Drug-induced and toxin-induced

1.4. Associated with

1.4.1. Connective tissue diseases

1.4.2. Human immunodeficiency virus infection

1.4.3. Portal hypertension

1.4.4. CHDs

1.4.5. Schistosomiasis

1.4.6. Chronic hemolytic anemia

1.5. Persistent PH of the newborn

1.6. Pulmonary veno-occlusive disease or pulmonary capillary hemangiomatosis

2. PH caused by left heart disease

\subsection{Systolic dysfunction}

2.2. Diastolic dysfunction

2.3. Valvular disease

3. PH caused by lung diseases or hypoxia

3.1. Chronic obstructive pulmonary disease (COPD)

3.2. Interstitial lung disease

3.3. Other pulmonary diseases with mixed restrictive and obstructive pattern

3.4. Sleep-disordered breathing

3.5. Alveolar hypoventilation disorders

3.6. Chronic exposure to high altitude

3.7. Developmental abnormalities

4. Chronic thromboembolic $\mathrm{PH}$

5. $\mathrm{PH}$ with unclear multifactorial mechanisms

5.1. Hematologic disorders: myeloproliferative disorders, splenectomy

5.2. Systemic disorders: sarcoidosis, pulmonary Langerhans cell histiocytosis: lymphangioleiomyomatosis, neurofibromatosis, vasculitis

5.3. Metabolic disorders: glycogen storage disease, Gaucher disease, thyroid disorders

5.4. Others: tumoral obstruction, fibrosing mediastinitis, chronic renal failure on dialysis

From Simonneau G, Robbins IM, Beghetti M, et al. Updated clinical classification of pulmonary hypertension. J Am Coll Cardiol 2009;54:S45; with permission.

of the development of successful operative repairs at an earlier age. There are now estimated to be nearly a million adults with CHD in North America, and, for the first time in medical history, more adults than children with congenital heart lesions. ${ }^{32}$

It is estimated that $5 \%$ to $10 \%$ of adults with $\mathrm{CHD}$ develop $\mathrm{PAH} .{ }^{22,33}$ Some studies estimate $4 \%$ to 
Box 2

Anatomic-pathophysiologic classification of congenital systemic-to-pulmonary shunts associated with PAH

1. Type

Simple pre-tricuspid shunts

Atrial septal defect

Ostium secundum

Sinus venosus

Ostium primum

Total or partial unobstructed anomalous pulmonary venous return

Simple post-tricuspid shunts

Ventricular septal defect (VSD)

Patent ductus arteriosus

Combined shunts

Complex congenital heart disease

Complete atrioventricular septal defect

Truncus arteriosus

Single ventricle physiology with unobstructed pulmonary blood flow

Transposition of the great arteries with VSD and/or patent ductus arteriosus

Other

2. Dimension

Hemodynamic

Restrictive (pressure gradient across the defect)

Nonrestrictive

Anatomic

Small to moderate (ASD $\leq 2 \mathrm{~cm}$ and VSD $\leq 1 \mathrm{~cm}$ )

Large (ASD $>2 \mathrm{~cm}$ and VSD $>1 \mathrm{~cm}$ )

3. Direction of shunt

Predominantly systemic-to-pulmonary

Predominantly pulmonary-to-systemic

Bidirectional

4. Associated cardiac and extracardiac abnor -malities

5. Repair status

Unoperated

Palliated

Repaired

Adapted from Simonneau G, Robbins IM, Beghetti M, et al. Updated clinical classification of pulmonary hypertension. J Am Coll Cardiol 2009;54:S47; with permission.
$10 \%$ of all patients with CHD develop Eisenmenger syndrome; however, this increases to as high as $30 \%$ in patients with unrepaired congenital defects. ${ }^{33-35}$ Worldwide, it is estimated that 3.2 million children are at risk for the development of $\mathrm{PAH}-\mathrm{CHD} .{ }^{24}$ Most of them do not develop Eisenmenger syndrome, particularly if cardiac repair occurs within the first 2 years of life. Worldwide, because of inequality of access to medical care, only some patients $(2 \%-15 \%)$ undergo reparative surgery. ${ }^{24}$ A large outcome study in PAH-CHD showed a prevalence of PAH in CHD of $5.8 \%$ and its presence increased all-cause mortality and cardiac complications, including heart failure and arrhythmias, more than 2-fold and 3-fold, respectively. ${ }^{36}$ In addition, the presence of PAH increased hospital days and intensive care unit days by more than 3-fold when compared with patients with CHD without PAH. Given the increased recognition of $\mathrm{CHD}$ in the pediatric population coupled with advances in surgical and medical management for congenital lesions, more patients with more complex congenital lesions are surviving to adulthood. These patients may present with various degrees of $\mathrm{PAH}$ in adulthood, underscoring the importance of adult cardiologists evolving their understanding of both $\mathrm{CHD}$ and $\mathrm{PAH}$.

\section{PATHOPHYSIOLOGY}

Increased pulmonary blood flow from systemic-topulmonary shunts is responsible for initiating a series of events responsible for causing changes in the pulmonary vasculature that lead to pulmonary obstructive arteriopathy and to an increase in PVR and PAH. ${ }^{10}$ Main risk factors for the development of PAH include the type and size of the underlying anatomic defect and magnitude of shunt. Initial dynamic PAH is reversible, if corrective surgery is performed before vascular changes become permanent. The potential for reversibility is difficult to assess, and there is a paucity of information in this regard. ${ }^{2}$

Most of the pathophysiologic processes in $\mathrm{PAH}$ CHD seem similar to the pathogenesis implicated in the development of other forms of PAH. The pathogenesis of PAH is explained by a persistent high flow and pressure in the pulmonary vasculature that causes endothelial damage, leading to loss of endothelial barrier function and imbalance of vasoactive mediators that favor vasoconstriction, inflammation, thrombosis, cell proliferation, apoptosis, and fibrosis and result in pulmonary vascular remodeling and irreversible $\mathrm{PAH} .{ }^{37} \mathrm{~A}$ more detailed description of the mechanisms involved in the development of PAH helps to understand current and potential future therapeutic interventions. 
The destruction of the vascular endothelial barrier causes degradation of the extracellular matrix as well as release of growth factors such as fibroblast growth factor, angiopoietin-1 and transforming growth factor $\beta$, which induces smooth muscle hypertrophy and proliferation. ${ }^{38}$ In addition, endothelial dysfunction leads to activation of cytokines and localized inflammatory cascades. ${ }^{39}$

The pulmonary endothelium is responsible for the production of many vascular mediators. With endothelial cell dysfunction, there is a shift toward vasoconstriction, cellular proliferation, and apoptosis caused by increased production and decreased destruction of vasoconstrictors (ie, endothelin-1 and thromboxane $\mathrm{A}_{2}$ ), as well as decreased production and increased destruction of vasodilators, such as nitric oxide (NO) and prostacyclin. Endothelin-1 is a potent vasoconstrictor that can cause smooth muscle proliferation as well, leading to vascular remodeling. Circulating endothelin levels have been found to correlatewith disease severity and outcome in idiopathic $\mathrm{PH},{ }^{40-42}$ although this mediator has been less extensively studied in Eisenmenger syndrome. ${ }^{16,43-45}$

The pulmonary endothelium is a major producer of NO. NO is endogenously synthesized by NO synthases and is a freely diffusible molecule that enters the pulmonary smooth muscle cells to produce guanosine $3^{\prime}, 5^{\prime}$-cyclic monophosphate (cGMP), resulting in vasodilation, helping keep the pulmonary vascular circuit at low pressure. ${ }^{46-48}$ Phosphodiesterases are responsible for breakdown of cGMP. With impaired production and normal degradation, cGMP levels decline, thereby decreasing cGMP-mediated vasodilation. ${ }^{16,49,50}$ Endothelial damage also causes a decrease in prostacyclin production, a potent vasodilator that also inhibits platelet aggregation and smooth muscle cell proliferation by increasing CAMP levels. ${ }^{8,16,21,51}$

Recent research has revealed a genetic predisposition $^{52}$ (because not all patients with CHD develop $\mathrm{PAH}$ ) and suggests the presence of other potential pathways involved in the pathogenesis of $\mathrm{PAH}-\mathrm{CHD}$, including downregulation of potassium channels, ${ }^{53}$ increased matrix metalloproteinases, ${ }^{54}$ decreased vasoactive intestinal peptide, ${ }^{55}$ increased serotoni ${ }^{56}$ and transforming growth factor $\beta$ levels, ${ }^{57}$ among others. ${ }^{58}$ Potential new biomarkers and lines of therapies could result from these discoveries. ${ }^{59}$

\section{CLINICAL PRESENTATION}

The clinical presentation of $\mathrm{PAH}-\mathrm{CHD}$ can be varied, and there is not a pathognomonic symptom pattern that can be easily identified. There are many different factors affecting the presenting symptoms: the underlying congenital defect, the repair status, and the degree of initial and residual shunting. Symptoms from $\mathrm{PH}$ itself are also nonspecific and include breathlessness, fatigue, chest pain, and syncope. Depending on the severity of $\mathrm{PH}$, there may be cyanosis and clubbing. Most left-toright congenital shunts do not initially have cyanosis, but its presence is often the harbinger of increasing pulmonary pressures and the development of Eisenmenger syndrome. ${ }^{13,20,60}$ Complex congenital lesions may have some degree of chronic cyanosis, making the identification of worsening cyanosis difficult. In advanced stages, patients develop progressive right ventricular dysfunction, which may result in sudden death.

\section{Exercise Intolerance}

Dyspnea on exertion is the most common presenting symptom. Many patients with CHD have some degree of exercise intolerance, particularly those with $\mathrm{PAH}$. Some estimates suggest that more than $90 \%$ of patients with $\mathrm{PAH}-\mathrm{CHD}$ have New York Heart Association (NYHA) class II or worse symptoms. As mentioned earlier, these patients progressively restrict their regular activity, which complicates accurate estimation of their functional capacity. ${ }^{61-64}$ Exercise intolerance is a nonspecific symptom, because it can represent $\mathrm{PAH}$ itself, hypoxemia, worsening heart failure, or deconditioning.

\section{Hemoptysis}

Hemoptysis is another common symptom in $\mathrm{PAH}-$ $\mathrm{CHD}$, and is most often present in patients with Eisenmenger syndrome. Hemoptysis is caused by the development of bronchial collaterals in patients with long-standing cyanosis. ${ }^{30}$ Case series and retrospective studies indicate that anywhere from $11 \%$ to $100 \%$ of patients present with hemoptysis. ${ }^{1,25,65-67}$ Although unsettling for most patients, hemoptysis is generally not a cause of mortality for these patients. ${ }^{25,65-67}$

\section{Pulmonary Embolism}

Given the extensive strain on the pulmonary arterial system, as well as turbulent flow, there is a higher risk of pulmonary thromboembolism in patients with $\mathrm{PAH}-\mathrm{CHD}$. Some case series report that up to $30 \%$ of patients with Eisenmenger syndrome present with clinically detectable intrapulmonary thrombus, usually manifested by rapidly worsening dyspnea, hemoptysis, chest pain, and tachycardia. ${ }^{68,69}$ 


\section{Hematologic Manifestations}

There are a few major hematologic manifestations, including reactive or secondary erythrocytosis and chronic thrombocytopenia. Depending on the level of hypoxemia, patients with $\mathrm{PAH}-\mathrm{CHD}$ develop compensatory erythrocytosis, which when severe can lead to hyperviscosity syndrome, the manifestations of which include headaches, blurry vision, dizziness, paresthesias, and myalgias. ${ }^{70-74}$ Patients with Eisenmenger syndrome are generally iron deficient, and iron supplementation (oral or intravenous) is often necessary.

Because of the chronic hypoxemia, the presence of PAH and the use of epoprostenol, most patients with Eisenmenger syndrome have chronic thrombocytopenia, platelet dysfunction, and difficulties with clotting. ${ }^{73-76}$ In addition, passive congestion of the liver because of worsening right heart failure can lead to deficiencies in clotting factor production. As a result, some patients may present with bleeding, although this is usually a late manifestation of the syndrome.

\section{Infectious Considerations}

Patients with congenital shunt lesions and coexistent cyanosis are at particularly high risk of bacterial endocarditis. Studies suggest that risk of development of endocarditis in unrepaired ventricular septal defects may be as high as $13 \%$ lifetime. ${ }^{40}$ The risk in patients with Eisenmenger syndrome seems even more substantial ( $4 \%$ in 1 series over only 2 years of follow-up). Another infectious complication is cerebral abscess, presumably from septic emboli, with an incidence of more than $6 \%$ in patients with Eisenmenger syndrome followed for a 6 -year period. ${ }^{65}$

\section{Arrhythmias}

Arrhythmias are often a late manifestation in patients with Eisenmenger syndrome and the most common cause of death. Patients with Eisenmenger syndrome are at significantly increased risk of sudden cardiac death, ${ }^{66}$ with ventricular arrhythmias being the presumed cause. These arrhythmias result from a multitude of factors including structural heart lesions, electrolyte abnormalities, and worsening heart failure. Supraventricular arrhythmias are also common, with 1 study reporting supraventricular arrhythmias in $42 \%$ of patients on 24-hour Holter monitoring.

\section{Other}

Less frequently reported complications associated with $\mathrm{PH}$ in patients with $\mathrm{CHD}$ include bile stones, hyperuricemia and gout, acute renal injury associated with both hyperuricemia and glomerular injury, hepatic dysfunction, and cerebrovascular disease. ${ }^{76-79}$

\section{DIAGNOSIS}

\section{History and Physical Examination}

The history and physical examination are often insufficient to tease out PAH-CAD as the cause of $\mathrm{PH}$. However, they are helpful in identifying when further investigation is necessary. It is important to inquire into the onset, severity, and progression of symptoms, because it may help to assess the severity of the condition. ${ }^{20,60}$ In addition, associated symptoms may suggest a particular cause of $\mathrm{PH}$.

Underlying conditions can give some insight into other causes of $\mathrm{PH}$, such as a history of malignancy, which may be associated with chronic thromboembolic pulmonary disease, COPD, which can indicate $\mathrm{PH}$ associated with lung disease, and cardiovascular risk factors such as diabetes, which can point toward left heart failure. All of these conditions may also coexist with CHD.

Particular attention should be placed on determining the type of heart defect and the timing and nature of the corrective procedures, because these can alter the natural history of the disease. In general, patients with CHD have a more insidious course, thus a more insightful line of questioning may be necessary. For example, asking whether a patient is dyspneic may not be enough. ${ }^{20,60}$ On the other hand, asking what activities the patient was able to do a few months ago but is not able to do now may provide more detailed information.

Physical examination in a patient with CHD may show cyanosis and clubbing of the fingernails and toenails. If the unrepaired defect is a patent ductus arteriosus, the feet may be cyanosed and clubbed, whereas the right and possibly also the left arm may be spared (pink and unclubbed), depending on the location of the duct. This finding is pathognomonic for an Eisenmenger ductus. There may be a prominent second pulmonic sound associated with increased pulmonary pressures, although this finding is often subtle. It is important to assess for $\$ 3$ gallops, suggestive of heart failure and other valvular heart defects. ${ }^{60}$ It is also important to perform a thorough cardiopulmonary examination, specifically looking for the typical findings found with atrial septal defects, ventricular septal defects, and patent ductus arteriosus, taking into account that as the PVR increases, the shunt decreases and most of the classic murmurs disappear. 


\section{Routine Laboratory Testing}

Every patient with CHD should undergo routine laboratory evaluation, including complete blood counts, serum electrolytes, blood urea nitrogen, serum creatinine, and liver function tests. Specifically, it is important to assess for erythrocytosis, because a hematocrit level greater than $65 \%$ can be associated with hyperviscosity. ${ }^{80}$ Given the propensity for arrhythmias, it is important to check for serum electrolytes, specifically potassium, magnesium, and calcium. Evaluation of the patient's renal function and liver function tests is also important for therapeutic monitoring.

Brain natriuretic peptide (BNP) and $\mathrm{N}$-terminal pro-BNP have both been shown to be increased in pediatric and adult patients with $\mathrm{CHD}$, both with and without PAH. ${ }^{81,82}$ The lack of specificity makes these tests not particularly useful for the diagnosis of PAH. However; multiple studies have shown BNP to correlate with exercise capacity, response to therapy, and overall survival. ${ }^{41,81}$

\section{Chest Radiography}

The chest radiograph (CXR) is a sensitive, albeit nonspecific test. It is not particularly useful for diagnosis, prognosis, or treatment monitoring. Some studies have suggested that $\sim 90 \%$ of patients with PAH have an abnormal CXR at the time of presentation, most often increased central pulmonary vascular congestion with loss of peripheral vessels. ${ }^{83}$ On occasion, an abnormal CXR may reveal intrinsic lung disease that can motivate further evaluation.

\section{Echocardiogram}

Every patient with $\mathrm{CHD}$ should have at the least a transthoracic echocardiogram performed, ideally with a performing sonographer and an interpreting cardiologist with $\mathrm{CHD}$ experience. This test is important not only in the evaluation for congenital defects but also to estimate pulmonary pressure and assess for right ventricular strain. In addition, it assesses left ventricular function as a cause or contributor to $\mathrm{PH}$ and facilitates noninvasive monitoring after initiation of therapy or when symptoms progress. ${ }^{22,84,85}$ Subcostal images from a transthoracic echocardiogram in Fig. 1 show a large ventricular septal defect with evidence of bidirectional shunting, suggesting advanced $\mathrm{PAH}-\mathrm{CHD}$.

\section{Cardiac Catheterization}

Every patient with $\mathrm{PH}$ should be evaluated with a cardiac catheterization before initiation of $\mathrm{PAH}-$ specific therapy. The importance of this strategy is most evident in the CHD population, in whom pure PAH is often the exception rather than the rule. In the original Boston Adult Congenital Heart Cohort more than $80 \%$ of patients with CHD had coexistent triggers for increased pulmonary pressure outside PAH. These triggers included increased left-sided pressures, pulmonary artery or vein stenoses, and thromboembolic disease (Dr Michael J. Landzberg, personal communication, 2011). Similarly, in our cohort of patients with presumed $\mathrm{PAH}-\mathrm{CHD}$ at the Cleveland Clinic, we have found other causes responsible for pulmonary pressure increase in more than onethird of patients. Empiric therapy with a selective pulmonary vasoactive therapy in lieu of catheterization in such patients may be detrimental. Certain patient populations such as those with repaired tetralogy of Fallot deserve closer attention when increased right-sided pressure is found on echocardiography. In such patients, a variety of other associated lesions can be responsible for increased right-sided pressures, including unexpected right ventricular outflow obstruction, peripheral pulmonic stenosis(es), and aortopulmonary collaterals.

The cardiac catheterization in the patient with PAH-CAD should include a full oximetry run to assess for the presence of shunting and to quantify the direction of this shunt. Fig. 2 shows the stages of progression in a patient with a large ventricular septal defect, with notation made regarding the expected saturations in each heart chamber. Early in the disease process (see Fig. 2A) the shunt is left to right and large resulting in a significant step up in oxygenation at the level of the right ventricle. As the disease progresses (see Fig. 2B), the shunt progressively decreases as the PVR rises. Late in the disease process (see Fig. 2C), the PVR is large and the shunt reverses (becomes right to left). Also the cardiac output is reduced, as shown by the decreased saturation of the mixed venous (right atrial) blood.

Ideally, a vasodilator challenge should also be performed during catheterization, with careful attention to the impact on the amount and direction of the shunt. In some cases, balloon occlusion of the defect can be helpful to assess the impact on pulmonary pressures. In such cases, simultaneous measurement of pulmonary and systemic pressures during the occlusion is essential. We have found that a significant decrease in PVR identifies patients in whom repair is still feasible, whereas a decrease in systemic pressure during occlusion should be an ominous sign and absolute contraindication to defect repair.

The vasodilator challenge also seems to predict prognosis in patients with CHD. Inhaled NO 


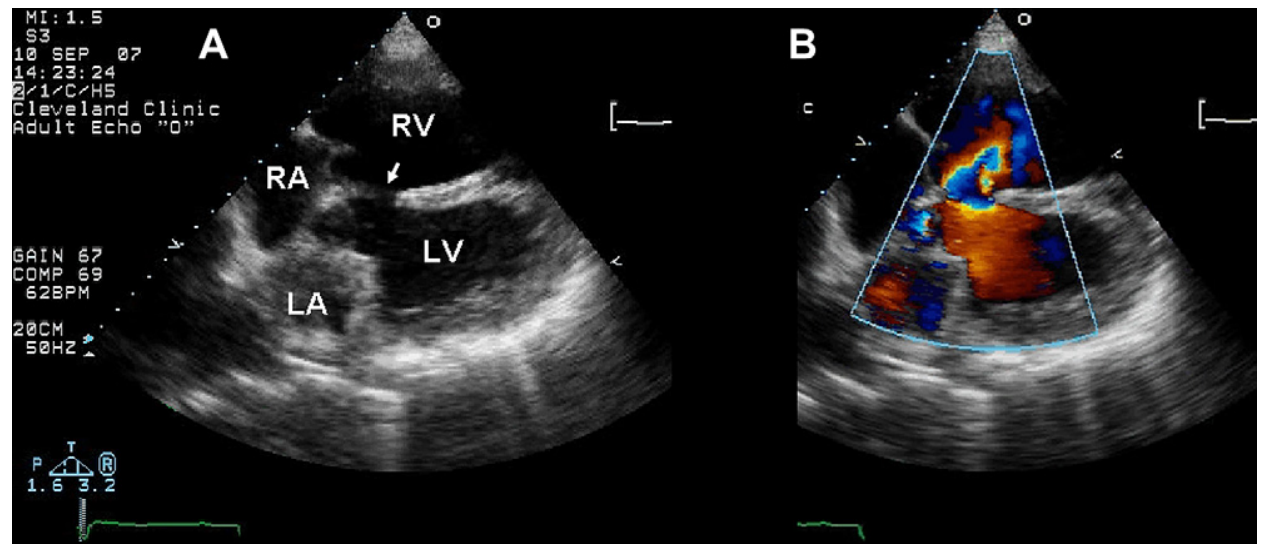

Fig. 1. Subcostal images from a transthoracic echocardiogram in a patient with a large ventricular septal defect (arrow) and PH. Images are without $(A)$ and with $(B)$ color Doppler applied. LA, left atrium; LV, left ventricle; RA, right atrium; RV, right ventricle.
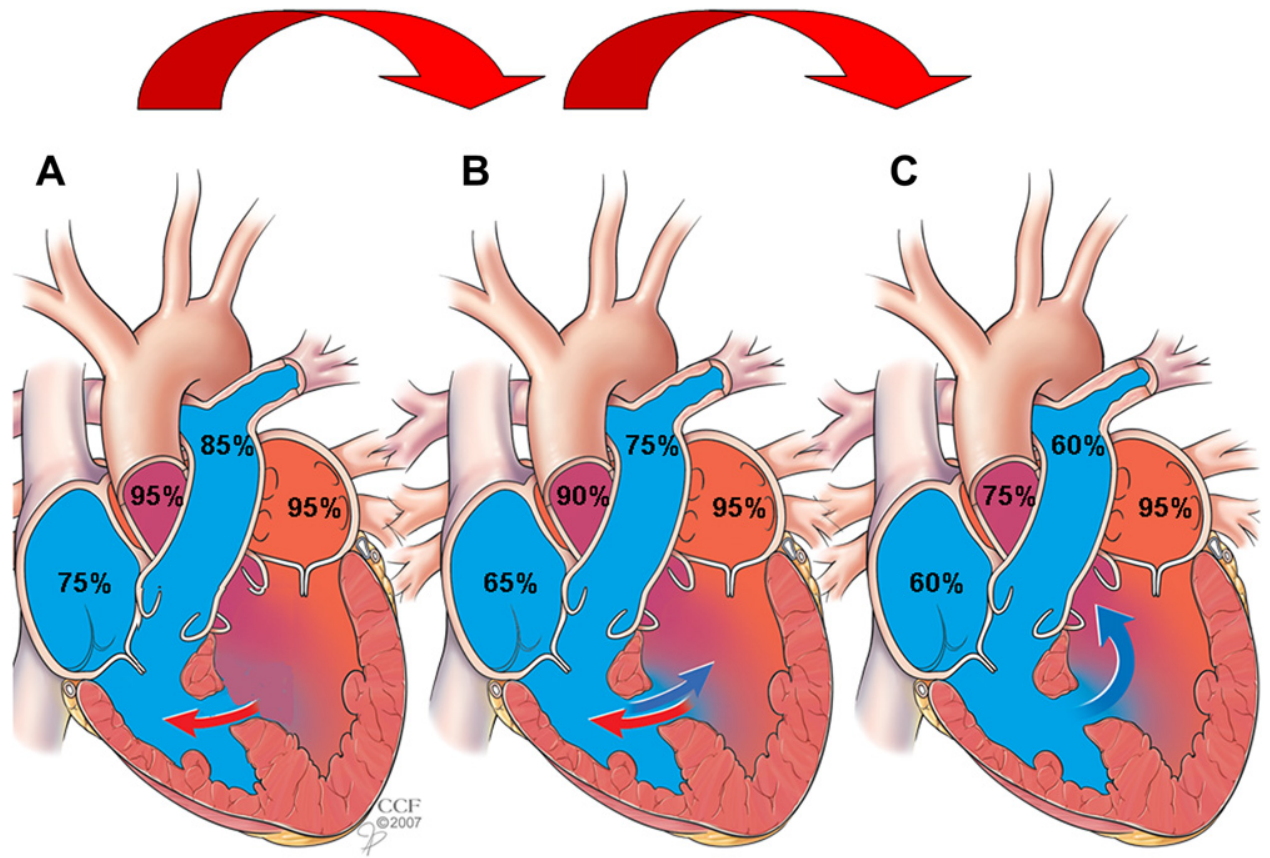

Fig. 2. The stages of progression of pulmonary vascular disease in a patient with a large ventricular septal defect (the arrows signify the flow of blood across the ventricular septal defect). The chambers are annotated with the oxygen saturations. Early in the disease process $(A)$ the shunt is left to right and large. The right atrial saturation (equal to the mixed venous saturation) is $75 \%$ and increases to $85 \%$ beyond the right ventricle because of the shunt. The left atrial and aortic saturations are the same because no right to left shunt is present. As the disease progresses $(B)$, the shunt is progressively reduced as the PVR rises. The cardiac output is starting to decrease as a result of the development of right ventricular dysfunction (decreased to $65 \%$ ). There remains some left to right shunting (pulmonary artery saturation is $75 \%$ ) but the aortic saturation (90\%) is now lower than the left atrial saturation (95\%) because some right to left shunting (bidirectional shunt) is present. Late in the disease process $(C)$, the PVR is large and the shunt is fully reversed (right to left). The cardiac output is now even more reduced (right atrial saturation is $60 \%$ ) and no step-up in saturation is now seen. A substantial decrease in aortic saturation (75\%) is present as a result of the large right to left shunt. (Courtesy of Cleveland Clinic Foundation, Cleveland, $\mathrm{OH}$; with permission.) 
combined with oxygen can help identify candidates for corrective cardiac surgery and in addition identify patients with better long-term clinical outcome. ${ }^{86-90}$

Left heart catheterization may be necessary to confirm the LVEDP if the PCWP is difficult to obtain or interpret. Coronary angiography may also be needed to assess for atherosclerosis in older patients.

Current European and American College of Cardiology (ACC)/American Heart Association (AHA) guidelines strongly recommend a baseline right heart catheterization with a vasodilator challenge for both diagnostic purposes and before initiating therapy. In addition, monitoring for efficacy of PAH therapy invasively is suggested, although no time frame for repeating catheterization is provided. ${ }^{22,84,85}$

\section{Exercise Testing}

Formal exercise testing serves multiple purposes, which include assessing the severity of disease, determining prognosis, and evaluating the effectiveness of therapy. Two methods to assess exercise tolerance are the 6-minute walk test (6MWT) and cardiopulmonary exercise testing. Motivated by its simplicity, most studies in $\mathrm{PH}$ use the 6MWT to assess response to therapy. ${ }^{62-64,91}$ Current guidelines recommend exercise testing before initiating therapy and at 3-month to 6month intervals thereafter. ${ }^{22,85}$

\section{Advanced Studies}

More advanced studies such as transesophageal echocardiography, cardiac magnetic resonance imaging, V/Q scanning, and pulmonary function testing should be performed only if clinically indicated and if they are not part of the routine workup..$^{22,85}$

\section{TREATMENT}

\section{General Principles of Therapy}

Patients with $\mathrm{PAH}-\mathrm{CHD}$ should be monitored at regular intervals by experienced physicians to assess for changes in symptom profile, vital signs, complete blood counts, and electrolytes. The treatment strategy is for the most part based on clinical experience rather than being evidencebased. ${ }^{30}$ Patients with Eisenmenger syndrome, in particular, should be managed in centers with experience in the treatment of this syndrome. ${ }^{22}$

A treatment approach for $\mathrm{PAH}-\mathrm{CHD}$ similar to other causes of $\mathrm{PAH}$ has recently been proposed (Fig. 3). ${ }^{92}$ Parts of this algorithm have been derived primarily from studies in idiopathic disease and
PAH associated with connective tissue disease, therefore care should be taken when extrapolating these data to PAH-CHD. ${ }^{30}$

\section{Oxygen therapy}

Most patients with $\mathrm{CHD}$, depending on the degree of shunting, have a degree of chronic hypoxia. Oxygen therapy does not improve exercise tolerance or survival in these patients; however, some patients still receive oxygen to use with exertion or on a nocturnal basis, based on symptom relief. ${ }^{93}$ Care should be exercised not to overoxygenate these patients, because this may depress their respiratory drive and lead to further hypoxia. Also because these patients are prone to bleeding, because of the hematologic issues mentioned earlier, high-flow nasal cannula oxygen can result in epistaxis, with all of its attendant problems.

\section{Aerobic exercise}

Aerobic exercise is often avoided by patients with $\mathrm{CHD}$ because of worsening dyspnea. However, it is important to encourage continued aerobic exercise to improve exercise tolerance. However, it is recommended to avoid strenuous exercise. ${ }^{22}$

\section{Anticoagulation}

There is a paucity of evidence regarding anticoagulation in patients with PAH-CHD. Therefore, current practice is varied and fragmented. Most centers anticoagulate these patients given their prothrombotic propensity. ${ }^{25,68,69,73}$ However, because of the increased risk of hemorrhage and hemoptysis, anticoagulation should be carefully monitored. ${ }^{22,25}$

\section{Antibiotic prophylaxis}

Patients with $\mathrm{CHD}$ are at a markedly increased risk of infectious complications, specifically bacterial endocarditis. ${ }^{40,66}$ Current ACC/AHA guidelines recommend antibiotic prophylaxis for invasive dental procedures (any procedure involving gum manipulation) in unrepaired patients with cyanotic $\mathrm{CHD}$, patients with residual defects at the site or adjacent to the site of a prosthetic patch or prosthetic device that prevents endothelialization after repair, and for any patients within 6 months of surgical or percutaneous repairs using prosthetic materials or devices. ${ }^{84,94,95}$ We further propose that any patient with $\mathrm{CHD}$, repaired or unrepaired, who has associated $\mathrm{PH}$ should receive appropriate prophylactic antibiotics before dental procedures, given their complexity and poor clinical reserve. 
PAH associated with congenital cardiac shunts and Eisenmenger's Syndrome

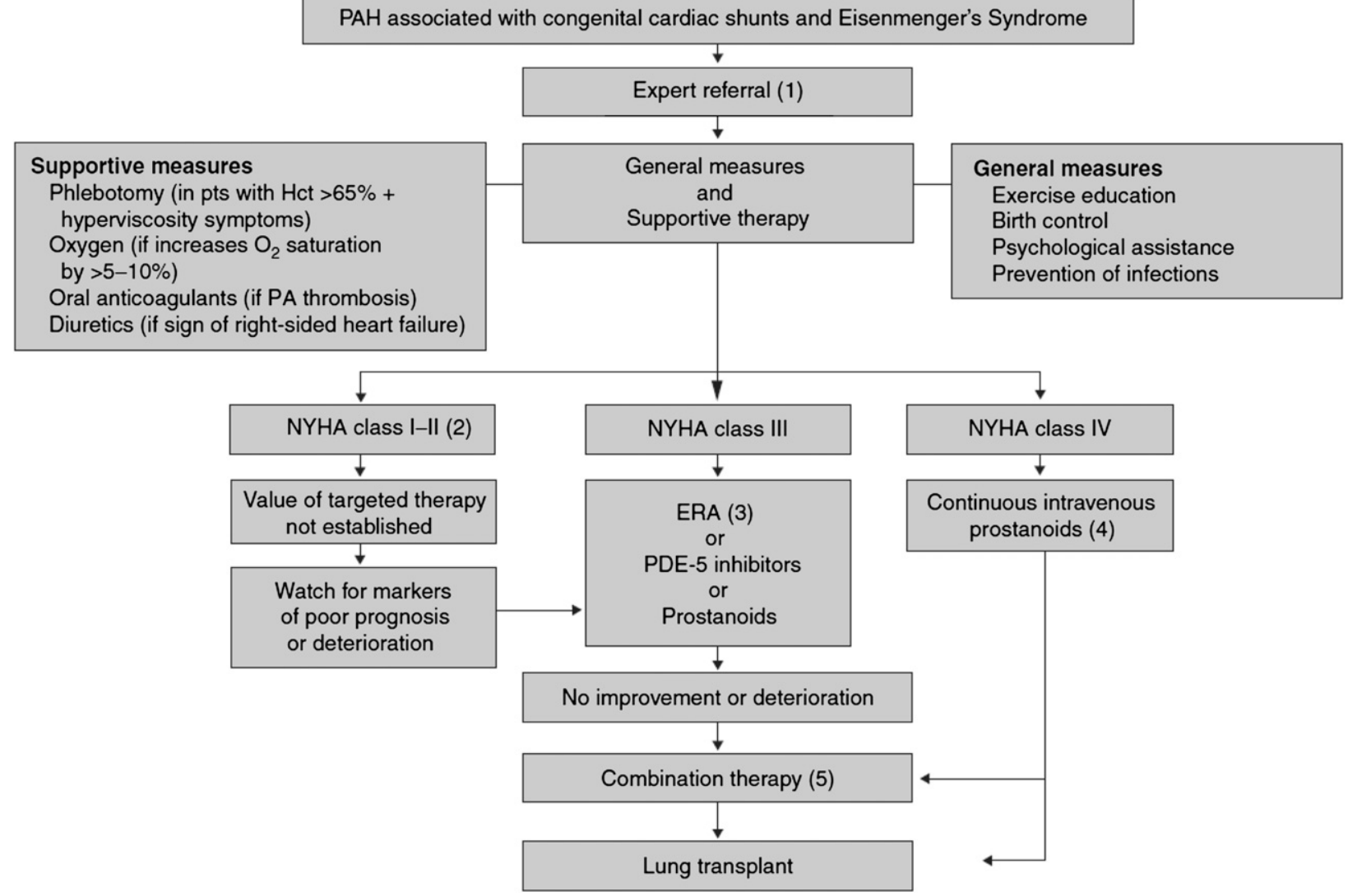

Fig. 3. Treatment algorithm for PAH-CHD. (1) Because of the complexity of the condition and the multiple treatment options available, expert referral is recommended. (2) Patients can remain clinically stable for prolonged periods and the efficacy/safety ratio of different therapies in these groups is not clear. (3) More evidence supports the use of bosentan. (4) Unstable patients should be treated with intravenous prostacyclin analogues, based on expert opinion. (5) In the absence of improvement or deterioration, combination therapy should be considered. (Reproduced from Galie N, Manes A, Palazzini M, et al. Management of pulmonary arterial hypertension associated with congenital systemic-to-pulmonary shunts and Eisenmenger's syndrome. Drugs 2008;68:1062; with permission.) 


\section{Diuretics, digitalis, antiarrhythmics, and calcium-channel blockers}

Diuretics and digitalis are often used on an individual patient basis in Eisenmenger syndrome, with the precaution of avoiding dehydration, which can worsen hyperviscosity and produce hypotension. ${ }^{29}$ Supraventricular and ventricular arrhythmias are common and may lead to hemodynamic decompensation and sudden death. ${ }^{60}$ Amiodarone is often used, and the role of implantable defibrillators is unknown. ${ }^{67}$ None of these approaches has significantly modified survival or risk of deterioration. ${ }^{66}$ Calcium-channel blockers are generally contraindicated in patients with Eisenmenger syndrome because of their negative inotropic effects and systemic vasodilation (which increases right-to-left shunt and can worsen cyanosis). ${ }^{22,92,96}$

\section{Treatment of hyperviscosity syndrome}

Patients with hematocrit levels greater than $65 \%$ are at increased risk of hyperviscosity syndrome. When clinical judgment warrants phlebotomy for relief of symptoms of hyperviscosity, care needs to be taken to avoid air embolization and the risk of stroke. ${ }^{70,73,77}$ Also, because these patients are sensitive to volume, adequate volume replacement is an important part of this therapy. Routine phlebotomy in cyanotic patients with CHD is associated with worsening exercise tolerance and increased risk of stroke, and therefore should be avoided. ${ }^{70}$ In addition, monitoring for and treatment of iron deficiency is important, to ensure adequate hematopoiesis and erythrocytosis that is appropriate to the level of hypoxemia. 22,29

\section{Avoidance of pregnancy}

$\mathrm{CHD}$ associated with $\mathrm{PH}$ is associated with a significantly increased risk of maternal and fetal morbidity and mortality. Some estimates suggest up to a $50 \%$ risk of maternal mortality and $40 \%$ risk of spontaneous abortion in patients with Eisenmenger syndrome. ${ }^{97-99}$ These patients have an increased risk of cardiovascular events during birth, manifested as a higher incidence of arrhythmia, heart failure, and embolic events. ${ }^{100}$ Therefore, pregnancy should be strongly discouraged in these patients. In individuals who become pregnant and do not wish to undergo elective abortion, careful monitoring and a multidisciplinary approach are essential.

For contraception, intrauterine devices impregnated with progesterone may be the best option, given theirs overall effectiveness and decreased risk of systemic thrombosis. Oral estrogen-based contraception is associated with an increased risk of thromboembolic events, and therefore is not ideal in these patients. Oral progesterone- based contraception has a high failure rate, and surgical options carry with them considerable perioperative risk.

\section{Specific $\mathrm{PH}$ therapeutic options}

Randomized controlled trials that have shown benefits of $\mathrm{PH}$-specific therapies in patients with $\mathrm{PAH}$ have included a few individuals with Eisenmenger syndrome. This important limitation complicates the treatment strategy for these patients. $\mathrm{PAH}$-specific therapies center around 3 major pathways: endothelin, $\mathrm{NO}$, and prostacyclin.

Endothelin receptor antagonists Endothelin receptor antagonists (ERAs) are the most extensively studied class of medications for PAH-CHD. Three drugs in this class have been studied in patients with PAH: bosentan, ambrisentan, and sitaxsentan. ${ }^{30}$ Bosentan (Tracleer) is a dual ERA that acts on both endothelin A and $B$ receptors. Until recently, there had only been small-scale, openlabel trials, which suggested efficacy of oral bosentan in patients with PAH-CHD. ${ }^{87,101-108}$ The BREATHE-5 (Bosentan Randomized Trial of Endothelin Antagonist Therapy-5) trial was the first large (bosentan $n=37$, placebo $n=17$ ), randomized, double-blind, placebo-controlled trial looking at bosentan in World Health Organization (WHO) class III Eisenmenger syndrome. At 16 weeks, bosentan significantly improved exercise capacity (patients were able to walk $53.1 \mathrm{~m}$ more during 6MWT) and reduced PVR index $\left(-472\right.$ dyn $\left.\mathrm{s} / \mathrm{cm}^{5}\right)$ and mean pulmonary artery pressure $(-5.5 \mathrm{~mm} \mathrm{Hg})$ compared with placebo. In addition, bosentan did not worsen oxygen saturation. ${ }^{109} \mathrm{~A}$ post hoc analysis showed no difference in efficacy within different types of congenital defects. ${ }^{110}$ Long-term data have shown that the improvement on bosentan can be maintained without safety or tolerability issues. ${ }^{111-116}$ A more recent randomized controlled trial of bosentan in patients with NYHA functional class II PAH included patients with $\mathrm{PAH}-\mathrm{CHD}(\mathrm{n}=32$ of 185 individuals). At 6 months, PVR significantly decreased from baseline but 6MWT distance change did not reach statistical significance (mean treatment effect $19.1 \mathrm{~m}, P=.076$ ). ${ }^{117}$ There appeared to be no difference in the short-term clinical response between adults and children with $\mathrm{PAH}$ associated with systemic-to-pulmonary shunts. Several studies have shown continued benefit in exercise tolerance (6MWT), NYHA functional class, and physical/mental health (Short Form-36 score), as far as 5 years from initiation of therapy. This benefit is more robust in patients with PAH-CHD without Down syndrome. ${ }^{118-121}$ The predominant adverse reaction of bosentan is increased hepatic transaminases, which can be 
seen up to $\sim 10 \%$ of patients. ${ }^{105,116}$ However, the distinct benefit is that it is an oral agent and simple to administer. Dosage is generally initiated at 62.5 $\mathrm{mg}$ twice daily and uptitrated to $125 \mathrm{mg}$ twice daily after 4 weeks.

Ambrisentan (Letaris) is a single ERA with preferential activity on the endothelin $A$ receptor. It was studied in 2 large randomized, double-blind, placebo-controlled trials with improved exercise tolerance (6MWT), functional class $(\mathrm{WHO})$, health survey score (Short Form-36 score), dyspnea score (Borg) and B-type natriuretic peptide in patients with PAH after 12 weeks of treatment. ${ }^{122,123}$ Patients with PAH-CHD were excluded from this study; however, a recent single-center study involving 17 patients showed short-term ( $\sim 6$ months) improvement in exercise capacity (6MWT). This beneficial response diminished during long-term follow-up ( $\sim 2.5$ years). ${ }^{124}$ Overall, there have been limited data with the use of this medication in PAH-CHD. Its benefits include better tolerance and less drugto-drug interaction than other ERAs. ${ }^{125}$

Phosphodiesterase type-5 inhibitors Phosphodiesterase type-5 (PDE-5) inhibitors, such as sildenafil (Revatio) and tadalafil (Adcirca), inhibit the breakdown of cGMP in smooth muscle cells, leading to enhanced cGMP-mediated vasodilation. In a large randomized, placebo-controlled study, patients with PAH (including patients with $\mathrm{PAH}-\mathrm{CHD}$ ) reported improvements in exercise capacity, WHO function class, and hemodynamics after 12 weeks of treatment. ${ }^{126}$ There have been limited data on PDE-5 inhibitors specifically in patients with Eisenmenger syndrome. ${ }^{126-133} \mathrm{~A}$ recent large prospective, open-label trial of sildenafil in PAH showed significant improvements in functional class, oxygen saturations, and cardiopulmonary hemodynamics after 6 months of treatment. ${ }^{127}$ Longer-term studies have suggested sustained benefits.

In a preliminary study, tadalafil showed efficacy and safety in a small group of symptomatic patients with Eisenmenger syndrome. ${ }^{132}$ There have also been multiple small trials with sildenafil used in addition to prostanoids, with improved exercise capacity and hemodynamics shown as well.

Prostacyclin analogues Intravenous epoprostenol (Flolan) is the most extensively studied medication in patients with $\mathrm{PAH}-\mathrm{CHD}$, particularly in patients with Eisenmenger syndrome. ${ }^{134,135}$ Several small studies have shown that continuous intravenous epoprostenol used in patients with Eisenmenger syndrome significantly improved function class, oxygen saturation, and exercise capacity and decreased PVR. ${ }^{134-137}$ Treprostinil (Remodulin) is another effective therapy with an acceptable safety profile in patients with $\mathrm{PAH}$. A randomized multicenter, double-blind study using treprostinil in PAH included 109 (of 469) patients with congenital systemic-to-pulmonary shunts. Improvement in exercise capacity was greater in sicker patients and was dose-related. Disease cause showed no significant interaction with the change in exercise capacity (+16 m on 6MWT). ${ }^{138}$ Beraprost (an oral prostanoid that is not commercially available in the United States) showed no improvements in exercise capacity in $\mathrm{PAH}$ causes other than idiopathic PAH. ${ }^{139}$

Inhaled prostanoids are also available (iloprost [Ventavis] and treprostinil [Tyvaso]), which have improved safety profiles, but their efficacy in PAH-CAD has not been well established. ${ }^{136,138-141}$ The use of subcutaneous or inhaled route of administration of prostanoids could prevent the risks associated with central lines in patients with Eisenmenger syndrome, including paradoxic embolism and sepsis, and deserves further study. ${ }^{134,135}$

Combination therapy A few studies have reported benefit to adding sildenafil to either bosentan ${ }^{142}$ or prostacyclin analogues. ${ }^{143-146}$ However, there has been no direct comparison among different classes of $\mathrm{PH}$-specific therapies or between monotherapy or combined therapy in patients with Eisenmenger syndrome. Because of the limited data available, the use of combination therapy should be considered on a case-by-case basis. ${ }^{92}$

\section{Transplantation}

Transplant-free survival is difficult to predict in patients with Eisenmenger syndrome. Some patients have prolonged survival despite severe hypoxemia. ${ }^{66}$ Before $\mathrm{PAH}$-specific therapy became available, patients with Eisenmenger syndrome had improved survival compared with idiopathic PAH (3-year survival of $77 \%$ vs $35 \%) .27$ This improved survival likely resulted from congenital adaptations of the right ventricle (the chamber remains hypertrophied after birth) and the presence of a shunt that prevented the development and limited the impact of suprasystemic pressures on the right ventricle. ${ }^{26}$ Recent data from the US Registry to Evaluate Early and Long-Term PAH Disease Management (REVEAL) analyzed 1-year survival data from 2176 consecutive patients with $\mathrm{PAH}$. Of patients with $\mathrm{PAH}$, $11.8 \%$ had PAH-CHD. Overall 1-year survival was $91 \%$, worse for patients with heritable, portopulmonary, and connective tissue disease-related PAH. CHD did not confer the expected survival advantage, regardless of the type of defect or the repair status. ${ }^{147}$ This finding suggests that 
withholding $\mathrm{PAH}$-specific therapy to patients with PAH-CHD because of presumed stability is a flawed strategy.

$\mathrm{PAH}$-specific therapies seem to stabilize patients with PAH-CHD as assessed by 6MWT, mean pulmonary arterial pressure, and PVR. ${ }^{148}$ Furthermore, 1 recent retrospective study has shown a substantial survival benefit (in both unadjusted and adjusted analyses) with PAH-specific therapies $(73.5 \%$ of patients received bosentan, $25 \%$ sildenafil, and $1.5 \%$ epoprostenol) in patients with Eisenmenger syndrome followed in a large tertiary referral center. The overall 5-year mortality was $23.3 \%$, and of the 52 patients who died, only 2 were on PAH-specific therapy. ${ }^{149}$

Perioperative mortality for transplantation is higher in CAD-PAH, but after this period some patients have an excellent response, with dramatic improvements in symptoms and quality of life. ${ }^{42,150-152}$ Transplant options include heartlung or lung transplantation, with concomitant heart defect repair. These options are reserved for special patients not responsive to medical treatment who have indicators of poor prognosis (syncope, refractory right heart failure, function class III/IV, or severe hypoxemia). ${ }^{153}$ By the time patients with $\mathrm{PAH}-\mathrm{CHD}$ are considered for transplantation, they are usually poor candidates because of multiple organ system failure. ${ }^{29,154}$

\section{Shunt closure in patients with Eisenmenger syndrome}

This is a controversial topic and there are only scatted case reports to assist in the decision of whether to close a hemodynamically significant shunt. ${ }^{155}$ Potential candidates may be patients with right-to-left or neutral shunt that receive $\mathrm{PAH}-$ specific therapy and subsequently experience a reversal of shunt (becoming left-to-right) both at rest and during activities. This intervention (treatand-repair) may improve oxygenation and pulmonary artery pressure at the expense of decreasing cardiac output. A careful selection of patients based on age, type of defect, resting, and exercise shunt hemodynamics is critical. ${ }^{155,156}$ Some experts suggest a PVR less than 6 Wood units per $\mathrm{m}^{2}$ and a PVR/systemic vascular resistance ratio of 0.3 or less, after initiation of PAH therapy, to consider shunt closure in previously inoperable CHD. ${ }^{157}$ In our personal experience, we have yet to witness a patient with true Eisenmenger syndrome who improved with therapy to the point that their lesion could be successfully repaired.

\section{Prevention}

Access to medical therapy is the single most important factor to prevent the development of irreversible $\mathrm{PH}^{24}$ It is recommended that children with large left-to-right shunts or increased PVR undergo operative closure of the defect in the first 12 to 18 months of life to prevent development of Eisenmenger syndrome. ${ }^{158}$ In children younger than 2 years, pulmonary vascular remodeling is usually reversible after the repair of the heart defect. ${ }^{10}$ Some conditions such as truncus arteriosus or transposition of the great arteries with ventricular septal defect are repaired during the first months of life, because they have higher propensity to develop $\mathrm{PAH} .{ }^{24}$ The level of PVR that precludes the safe closure of a heart defect varies with the age of the patient, type of lesion, PVR, and the presence of vasoreactivity. ${ }^{86,159-161}$ This topic remains a matter of significant controversy and outside the scope of this article.

\section{SUMMARY}

$\mathrm{PAH}-\mathrm{CHD}$ is common among the different subtypes of $\mathrm{PAH}$. Its severity depends on the type and size of the defect as well as the flow rate of the shunt. Cardiac catheterization is necessary for proper diagnosis and evaluation of severity. When reversibility is suspected, surgical or percutaneous correction is the treatment of choice. New PAH-specific therapies have proved beneficial, although further research is needed to determine optimal treatment of PAH-CHD. Lung or heart-lung transplantation remains an option for recalcitrant patients. More importantly, PAH may be preventable in many cases if the congenital heart defect(s) is identified and treated early.

\section{REFERENCES}

1. Wood P. The Eisenmenger syndrome or pulmonary hypertension with reversed central shunt. Br Med J 1958;2:755-62.

2. Steele PM, Fuster V, Cohen M, et al. Isolated atrial septal defect with pulmonary vascular obstructive disease-long-term follow-up and prediction of outcome after surgical correction. Circulation 1987;76:1037-42.

3. Evans W, Short DS. Pulmonary hypertension in congenital heart disease. Br Heart J 1958;20: 529-51.

4. Cherian G, Uthaman CB, Durairaj M, et al. Pulmonary hypertension in isolated secundum atrial septal defect: high frequency in young patients. Am Heart J 1983;105:952-7.

5. Haworth SG. Pulmonary vascular bed in children with complete atrioventricular septal defect: relation between structural and hemodynamic abnormalities. Am J Cardiol 1986;57:833-9. 
6. Newfeld EA, Sher M, Paul MH, et al. Pulmonary vascular disease in complete atrioventricular canal defect. Am J Cardiol 1977;39:721-6.

7. Campbell M. Natural history of ventricular septal defect. Br Heart J 1971;33:246-57.

8. Christman BW, McPherson CD, Newman JH, et al. An imbalance between the excretion of thromboxane and prostacyclin metabolites in pulmonary hypertension. N Engl J Med 1992;327:70-5.

9. Heath D, Edwards JE. The pathology of hypertensive pulmonary vascular disease; a description of six grades of structural changes in the pulmonary arteries with special reference to congenital cardiac septal defects. Circulation 1958;18:533-47.

10. Rabinovitch M, Haworth SG, Castaneda AR, et al. Lung biopsy in congenital heart disease: a morphometric approach to pulmonary vascular disease. Circulation 1978;58:1107-22.

11. Rabinovitch M, Keane JF, Norwood WI, et al. Vascular structure in lung tissue obtained at biopsy correlated with pulmonary hemodynamic findings after repair of congenital heart defects. Circulation 1984;69:655-67.

12. Besterman E. Atrial septal defect with pulmonary hypertension. Br Heart J 1961;23:587-98.

13. Diller GP, Gatzoulis MA. Pulmonary vascular disease in adults with congenital heart disease. Circulation 2007;115:1039-50.

14. Fasules JW, Tryka F, Chipman CW, et al. Pulmonary hypertension and arterial changes in calves with a systemic-to-left pulmonary artery connection. J Appl Physiol 1994;77:867-75.

15. Hoffman JI, Rudolph AM. The natural history of ventricular septal defects in infancy. Am J Cardiol 1965;16:634-53

16. Humbert M, Morrell NW, Archer SL, et al. Cellular and molecular pathobiology of pulmonary arterial hypertension. J Am Coll Cardiol 2004;43: 13S-24S.

17. Kidd L, Driscoll DJ, Gersony WM, et al. Second natural history study of congenital heart defects. Results of treatment of patients with ventricular septal defects. Circulation 1993;87:I38-51.

18. Niwa K, Perloff JK, Kaplan S, et al. Eisenmenger syndrome in adults: ventricular septal defect, truncus arteriosus, univentricular heart. J Am Coll Cardiol 1999;34:223-32.

19. Vongpatanasin W, Brickner ME, Hillis LD, et al. The Eisenmenger syndrome in adults. Ann Intern Med 1998;128:745-55.

20. Diller GP, Dimopoulos K, Okonko D, et al. Exercise intolerance in adult congenital heart disease: comparative severity, correlates, and prognostic implication. Circulation 2005; 112:828-35.

21. Badesch DB, Champion HC, Sanchez MA, et al. Diagnosis and assessment of pulmonary arterial hypertension. J Am Coll Cardiol 2009;54:S55-66.
22. Galie N, Hoeper MM, Humbert M, et al. Guidelines for the diagnosis and treatment of pulmonary hypertension: the Task Force for the Diagnosis and Treatment of Pulmonary Hypertension of the European Society of Cardiology (ESC) and the European Respiratory Society (ERS), endorsed by the International Society of Heart and Lung Transplantation (ISHLT). Eur Heart J 2009;30: 2493-537.

23. Simonneau G, Robbins IM, Beghetti M, et al. Updated clinical classification of pulmonary hypertension. J Am Coll Cardiol 2009;54:S43-54.

24. Adatia I, Kothari SS, Feinstein JA. Pulmonary hypertension associated with congenital heart disease: pulmonary vascular disease: the global perspective. Chest 2010;137:52S-61S.

25. Broberg C, Ujita M, Babu-Narayan S, et al. Massive pulmonary artery thrombosis with haemoptysis in adults with Eisenmenger's syndrome: a clinical dilemma. Heart 2004;90:e63.

26. Hopkins WE. The remarkable right ventricle of patients with Eisenmenger syndrome. Coron Artery Dis 2005;16:19-25.

27. Hopkins WE, Ochoa LL, Richardson GW, et al. Comparison of the hemodynamics and survival of adults with severe primary pulmonary hypertension or Eisenmenger syndrome. J Heart Lung Transplant 1996;15:100-5.

28. van Albada ME, Berger RM. Pulmonary arterial hypertension in congenital cardiac disease-the need for refinement of the Evian-Venice classification. Cardiol Young 2008;18:10-7.

29. Dimopoulos K, Giannakoulas G, Wort SJ, et al. Pulmonary arterial hypertension in adults with congenital heart disease: distinct differences from other causes of pulmonary arterial hypertension and management implications. Curr Opin Cardiol 2008;23:545-54.

30. Beghetti M, Galie N. Eisenmenger syndrome a clinical perspective in a new therapeutic era of pulmonary arterial hypertension. J Am Coll Cardiol 2009; 53:733-40.

31. Marelli AJ, Mackie AS, lonescu-Ittu R, et al. Congenital heart disease in the general population: changing prevalence and age distribution. Circulation 2007;115:163-72.

32. Marelli AJ, Therrien J, Mackie AS, et al. Planning the specialized care of adult congenital heart disease patients: from numbers to guidelines; an epidemiologic approach. Am Heart J 2009; 157:1-8.

33. Engelfriet PM, Duffels MG, Moller T, et al. Pulmonary arterial hypertension in adults born with a heart septal defect: the Euro Heart Survey on adult congenital heart disease. Heart 2007;93:682-7.

34. Friedman WF. Proceedings of National Heart, Lung, and Blood Institute pediatric cardiology 
workshop: pulmonary hypertension. Pediatr Res 1986;20:811-24.

35. Duffels MG, Engelfriet PM, Berger RM, et al. Pulmonary arterial hypertension in congenital heart disease: an epidemiologic perspective from a Dutch registry. Int J Cardiol 2007;120:198-204.

36. Lowe BS, Therrien J, Ionescu-Ittu R, et al. Diagnosis of pulmonary hypertension in the congenital heart disease adult population impact on outcomes. J Am Coll Cardiol 2011;58:538-46.

37. Rabinovitch M. Pulmonary hypertension: pathophysiology as a basis for clinical decision making. J Heart Lung Transplant 1999;18:1041-53.

38. Du L, Sullivan CC, Chu D, et al. Signaling molecules in nonfamilial pulmonary hypertension. N Engl J Med 2003;348:500-9.

39. Diller GP, van Eijl S, Okonko DO, et al. Circulating endothelial progenitor cells in patients with Eisenmenger syndrome and idiopathic pulmonary arterial hypertension. Circulation 2008;117:3020-30.

40. Shah $P$, Singh WS, Rose $V$, et al. Incidence of bacterial endocarditis in ventricular septal defects. Circulation 1966;34:127-31.

41. Trojnarska O, Gwizdala A, Katarzynski S, et al. The BNP concentrations and exercise capacity assessment with cardiopulmonary stress test in cyanotic adult patients with congenital heart diseases. Int J Cardiol 2010;139:241-7.

42. Berman EB, Barst RJ. Eisenmenger's syndrome: current management. Prog Cardiovasc Dis 2002; 45:129-38.

43. Hassoun PM, Thappa V, Landman MJ, et al. Endothelin 1: mitogenic activity on pulmonary artery smooth muscle cells and release from hypoxic endothelial cells. Proc Soc Exp Biol Med 1992;199:165-70.

44. Zamora MR, Stelzner TJ, Webb S, et al. Overexpression of endothelin-1 and enhanced growth of pulmonary artery smooth muscle cells from fawnhooded rats. Am J Physiol 1996;270:L101-9.

45. Cacoub P, Dorent R, Maistre G, et al. Endothelin-1 in primary pulmonary hypertension and the Eisenmenger syndrome. Am J Cardiol 1993;71:448-50.

46. Giaid A, Saleh D. Reduced expression of endothelial nitric oxide synthase in the lungs of patients with pulmonary hypertension. N Engl J Med 1995; 333:214-21.

47. Cooper CJ, Landzberg MJ, Anderson TJ, et al. Role of nitric oxide in the local regulation of pulmonary vascular resistance in humans. Circulation 1996;93:266-71.

48. Moncada S, Higgs A. The L-arginine-nitric oxide pathway. N Engl J Med 1993;329:2002-12.

49. Michelakis ED, Tymchak W, Noga M, et al. Longterm treatment with oral sildenafil is safe and improves functional capacity and hemodynamics in patients with pulmonary arterial hypertension. Circulation 2003;108:2066-9.
50. Rondelet B, Kerbaul F, Van Beneden R, et al. Signaling molecules in overcirculation-induced pulmonary hypertension in piglets: effects of sildenafil therapy. Circulation 2004;110:2220-5.

51. Tuder RM, Cool CD, Geraci MW, et al. Prostacyclin synthase expression is decreased in lungs from patients with severe pulmonary hypertension. Am J Respir Crit Care Med 1999;159:1925-32.

52. Roberts KE, McElroy JJ, Wong WP, et al. BMPR2 mutations in pulmonary arterial hypertension with congenital heart disease. Eur Respir J 2004;24: 371-4.

53. Newman JH, Fanburg BL, Archer SL, et al. Pulmonary arterial hypertension: future directions: report of a National Heart, Lung and Blood Institute/Office of Rare Diseases workshop. Circulation 2004;109: 2947-52.

54. Lepetit H, Eddahibi S, Fadel E, et al. Smooth muscle cell matrix metalloproteinases in idiopathic pulmonary arterial hypertension. Eur Respir J 2005; 25:834-42.

55. Petkov V, Mosgoeller W, Ziesche R, et al. Vasoactive intestinal peptide as a new drug for treatment of primary pulmonary hypertension. J Clin Invest 2003;111:1339-46.

56. Guignabert C, Izikki M, Tu LI, et al. Transgenic mice overexpressing the 5-hydroxytryptamine transporter gene in smooth muscle develop pulmonary hypertension. Circ Res 2006;98:1323-30.

57. Zaiman AL, Podowski M, Medicherla S, et al. Role of the TGF-beta/Alk5 signaling pathway in monocrotaline-induced pulmonary hypertension. Am J Respir Crit Care Med 2008;177:896-905.

58. Morrell NW, Adnot S, Archer SL, et al. Cellular and molecular basis of pulmonary arterial hypertension. J Am Coll Cardiol 2009;54:S20-31.

59. Erzurum S, Rounds SI, Stevens T, et al. Strategic plan for lung vascular research: an NHLBI-ORDR Workshop Report. Am J Respir Crit Care Med 2010;182:1554-62.

60. Diller GP, Dimopoulos K, Broberg CS, et al. Presentation, survival prospects, and predictors of death in Eisenmenger syndrome: a combined retrospective and case-control study. Eur Heart J 2006;27: 1737-42.

61. Dimopoulos K, Okonko DO, Diller GP, et al. Abnormal ventilatory response to exercise in adults with congenital heart disease relates to cyanosis and predicts survival. Circulation 2006;113:2796-802.

62. Paciocco G, Martinez FJ, Bossone E, et al. Oxygen desaturation on the six-minute walk test and mortality in untreated primary pulmonary hypertension. Eur Respir J 2001;17:647-52.

63. Miyamoto S, Nagaya N, Satoh T, et al. Clinical correlates and prognostic significance of sixminute walk test in patients with primary pulmonary hypertension. Comparison with cardiopulmonary 
exercise testing. Am J Respir Crit Care Med 2000; 161:487-92.

64. Wensel R, Opitz CF, Anker SD, et al. Assessment of survival in patients with primary pulmonary hypertension: importance of cardiopulmonary exercise testing. Circulation 2002;106:319-24.

65. Cantor WJ, Harrison DA, Moussadji JS, et al. Determinants of survival and length of survival in adults with Eisenmenger syndrome. Am J Cardiol 1999; 84:677-81.

66. Daliento L, Somerville J, Presbitero P, et al. Eisenmenger syndrome. Factors relating to deterioration and death. Eur Heart J 1998;19:1845-55.

67. Sreeram N. Eisenmenger syndrome: towards identifying the risk factors for death. Eur Heart J 2006; 27:1644-5.

68. Broberg CS, Ujita M, Prasad S, et al. Pulmonary arterial thrombosis in eisenmenger syndrome is associated with biventricular dysfunction and decreased pulmonary flow velocity. J Am Coll Cardiol 2007;50:634-42.

69. Silversides CK, Granton JT, Konen E, et al. Pulmonary thrombosis in adults with Eisenmenger syndrome. J Am Coll Cardiol 2003;42: 1982-7.

70. Broberg CS, Bax BE, Okonko DO, et al. Blood viscosity and its relationship to iron deficiency, symptoms, and exercise capacity in adults with cyanotic congenital heart disease. J Am Coll Cardiol 2006;48:356-65.

71. Gidding SS, Stockman JA 3rd. Erythropoietin in cyanotic heart disease. Am Heart J 1988;116:128-32.

72. Kontras SB, Bodenbender JG, Craenen J, et al. Hyperviscosity in congenital heart disease. J Pediatr 1970;76:214-20.

73. Perloff JK, Rosove MH, Child JS, et al. Adults with cyanotic congenital heart disease: hematologic management. Ann Intern Med 1988;109: 406-13.

74. Rosove MH, Perloff JK, Hocking WG, et al. Chronic hypoxaemia and decompensated erythrocytosis in cyanotic congenital heart disease. Lancet 1986;2: 313-5.

75. Lill MC, Perloff JK, Child JS. Pathogenesis of thrombocytopenia in cyanotic congenital heart disease. Am J Cardiol 2006;98:254-8.

76. Perloff JK. Systemic complications of cyanosis in adults with congenital heart disease. Hematologic derangements, renal function, and urate metabolism. Cardiol Clin 1993;11:689-99.

77. Ammash N, Warnes CA. Cerebrovascular events in adult patients with cyanotic congenital heart disease. J Am Coll Cardiol 1996;28:768-72.

78. Perloff JK, Latta H, Barsotti P. Pathogenesis of the glomerular abnormality in cyanotic congenital heart disease. Am J Cardiol 2000; 86:1198-204.
79. Perloff JK, Marelli AJ, Miner PD. Risk of stroke in adults with cyanotic congenital heart disease. Circulation 1993;87:1954-9.

80. Kaemmerer H, Fratz S, Braun SL, et al. Erythrocyte indexes, iron metabolism, and hyperhomocysteinemia in adults with cyanotic congenital cardiac disease. Am J Cardiol 2004;94:825-8.

81. Diller GP, Alonso-Gonzalez R, Kempny A, et al. B type natriuretic peptide concentrations in contemporary Eisenmenger syndrome patients: predictive value and response to disease targeting therapy. Heart 2012;98(9):736-42.

82. Knirsch W, Hausermann E, Fasnacht $M$, et al. Plasma B-type natriuretic peptide levels in children with heart disease. Acta Paediatr 2011; 100:1213-6.

83. Sheehan R, Perloff JK, Fishbein MC, et al. Pulmonary neovascularity: a distinctive radiographic finding in Eisenmenger syndrome. Circulation 2005;112:2778-85.

84. Warnes CA, Williams RG, Bashore TM, et al. ACC/ AHA 2008 Guidelines for the Management of Adults with Congenital Heart Disease: a report of the American College of Cardiology/American Heart Association Task Force on Practice Guidelines (writing committee to develop guidelines on the management of adults with congenital heart disease). Circulation 2008;118:e714-833.

85. McLaughlin VV, Archer SL, Badesch DB, et al. ACCF/AHA 2009 expert consensus document on pulmonary hypertension: a report of the American College of Cardiology Foundation Task Force on Expert Consensus Documents and the American Heart Association: developed in collaboration with the American College of Chest Physicians, American Thoracic Society, Inc., and the Pulmonary Hypertension Association. Circulation 2009;119: 2250-94.

86. Balzer DT, Kort HW, Day RW, et al. Inhaled nitric oxide as a preoperative test (INOP test I): the INOP Test Study Group. Circulation 2002;106:I76-81.

87. Post MC, Janssens S, Van de Werf F, et al. Responsiveness to inhaled nitric oxide is a predictor for mid-term survival in adult patients with congenital heart defects and pulmonary arterial hypertension. Eur Heart J 2004;25:1651-6.

88. D'Alto M, Romeo E, Argiento P, et al. Pulmonary vasoreactivity predicts long-term outcome in patients with Eisenmenger syndrome receiving bosentan therapy. Heart 2010;96:1475-9.

89. Budts W, Van Pelt N, Gillyns $H$, et al. Residual pulmonary vasoreactivity to inhaled nitric oxide in patients with severe obstructive pulmonary hypertension and Eisenmenger syndrome. Heart 2001; 86:553-8.

90. Goodwin TM, Gherman RB, Hameed A, et al. Favorable response of Eisenmenger syndrome to 
inhaled nitric oxide during pregnancy. Am J Obstet Gynecol 1999;180:64-7.

91. ATS statement: guidelines for the six-minute walk test. Am J Respir Crit Care Med 2002;166:111-7.

92. Galie N, Manes A, Palazzini M, et al. Management of pulmonary arterial hypertension associated with congenital systemic-to-pulmonary shunts and Eisenmenger's syndrome. Drugs 2008;68:1049-66.

93. Deanfield J, Thaulow E, Warnes C, et al. Management of grown up congenital heart disease. Eur Heart J 2003;24:1035-84.

94. Antibiotic prophylaxis of infective endocarditis. Recommendations from the Endocarditis Working Party of the British Society for Antimicrobial Chemotherapy. Lancet 1990;335:88-9.

95. Wilson W, Taubert KA, Gewitz M, et al. Prevention of infective endocarditis: guidelines from the American Heart Association. Circulation 2007;116:1736-54.

96. Montani D, Savale L, Natali D, et al. Long-term response to calcium-channel blockers in nonidiopathic pulmonary arterial hypertension. Eur Heart J 2010;31:1898-907.

97. Avila WS, Grinberg M, Snitcowsky R, et al. Maternal and fetal outcome in pregnant women with Eisenmenger's syndrome. Eur Heart J 1995;16:460-4.

98. Uebing A, Steer PJ, Yentis SM, et al. Pregnancy and congenital heart disease. BMJ 2006;332: 401-6.

99. Yentis SM, Steer PJ, Plaat F. Eisenmenger's syndrome in pregnancy: maternal and fetal mortality in the 1990s. Br J Obstet Gynaecol 1998;105:921-2.

100. Opotowsky AR, Siddiqi OK, D'Souza B, et al. Maternal cardiovascular events during childbirth among women with congenital heart disease. Heart 2012;98:145-51.

101. Apostolopoulou SC, Manginas A, Cokkinos DV, et al. Effect of the oral endothelin antagonist bosentan on the clinical, exercise, and haemodynamic status of patients with pulmonary arterial hypertension related to congenital heart disease. Heart 2005;91:1447-52.

102. Benza RL, Rayburn BK, Tallaj JA, et al. Efficacy of bosentan in a small cohort of adult patients with pulmonary arterial hypertension related to congenital heart disease. Chest 2006;129:1009-15.

103. Channick RN, Simonneau G, Sitbon O, et al. Effects of the dual endothelin-receptor antagonist bosentan in patients with pulmonary hypertension: a randomised placebo-controlled study. Lancet 2001; 358:1119-23.

104. Christensen DD, McConnell ME, Book WM, et al. Initial experience with bosentan therapy in patients with the Eisenmenger syndrome. Am J Cardiol 2004;94:261-3.

105. Gatzoulis MA, Rogers P, Li W, et al. Safety and tolerability of bosentan in adults with Eisenmenger physiology. Int J Cardiol 2005;98:147-51.
106. Gilbert N, Luther YC, Miera O, et al. Initial experience with bosentan (Tracleer) as treatment for pulmonary arterial hypertension (PAH) due to congenital heart disease in infants and young children. Z Kardiol 2005;94:570-4.

107. Rubin LJ, Badesch DB, Barst RJ, et al. Bosentan therapy for pulmonary arterial hypertension. N Engl J Med 2002;346:896-903.

108. Schulze-Neick I, Gilbert N, Ewert R, et al. Adult patients with congenital heart disease and pulmonary arterial hypertension: first open prospective multicenter study of bosentan therapy. Am Heart J 2005;150:716.

109. Galie N, Beghetti M, Gatzoulis MA, et al. Bosentan therapy in patients with Eisenmenger syndrome: a multicenter, double-blind, randomized, placebocontrolled study. Circulation 2006;114:48-54.

110. Berger RM, Beghetti M, Galie N, et al. Atrial septal defects versus ventricular septal defects in BREATHE-5, a placebo-controlled study of pulmonary arterial hypertension related to Eisenmenger's syndrome: a subgroup analysis. Int J Cardiol 2010; 144:373-8.

111. Gatzoulis MA, Beghetti M, Galie N, et al. Longerterm bosentan therapy improves functional capacity in Eisenmenger syndrome: results of the BREATHE-5 open-label extension study. Int J Cardiol 2008;127:27-32.

112. Apostolopoulou SC, Manginas A, Cokkinos DV, et al. Long-term oral bosentan treatment in patients with pulmonary arterial hypertension related to congenital heart disease: a 2-year study. Heart 2007;93:350-4.

113. D'Alto M, Vizza CD, Romeo E, et al. Long term effects of bosentan treatment in adult patients with pulmonary arterial hypertension related to congenital heart disease (Eisenmenger physiology): safety, tolerability, clinical, and haemodynamic effect. Heart 2007;93:621-5

114. Diaz-Caraballo E, Gonzalez-Garcia AE, Renones M, et al. Long-term bosentan treatment of complex congenital heart disease and Eisenmenger's syndrome. Rev Esp Cardiol 2009;62:1046-9.

115. Diller GP, Dimopoulos K, Kaya MG, et al. Long-term safety, tolerability and efficacy of bosentan in adults with pulmonary arterial hypertension associated with congenital heart disease. Heart 2007;93:974-6.

116. Mehta PK, Simpson L, Lee EK, et al. Endothelin receptor antagonists improve exercise tolerance and oxygen saturations in patients with Eisenmenger syndrome and congenital heart defects. Tex Heart Inst J 2008;35:256-61.

117. Galie N, Rubin L, Hoeper M, et al. Treatment of patients with mildly symptomatic pulmonary arterial hypertension with bosentan (EARLY study): a double-blind, randomised controlled trial. Lancet 2008;371:2093-100. 
118. Vis JC, Duffels MG, Mulder P, et al. Prolonged beneficial effect of bosentan treatment and 4-year survival rates in adult patients with pulmonary arterial hypertension associated with congenital heart disease. Int J Cardiol 2011. DOI:10.1016/j.ijcard.2011.06.064.

119. Avellana P, Segovia J, Sufrate E, et al. Long-term (5 years) effects of bosentan in patients with pulmonary arterial hypertension. Rev Esp Cardiol 2011; 64:667-73.

120. Monfredi O, Griffiths L, Clarke B, et al. Efficacy and safety of bosentan for pulmonary arterial hypertension in adults with congenital heart disease. Am J Cardiol 2011;108:1483-8.

121. van Loon RL, Hoendermis ES, Duffels MG, et al. Longterm effect of bosentan in adults versus children with pulmonary arterial hypertension associated with systemic-to-pulmonary shunt: does the beneficial effect persist? Am Heart J 2007; 154:776-82.

122. Galie N, Olschewski H, Oudiz RJ, et al. Ambrisentan for the treatment of pulmonary arterial hypertension: results of the ambrisentan in pulmonary arterial hypertension, randomized, double-blind, placebo-controlled, multicenter, efficacy (ARIES) study 1 and 2. Circulation 2008;117:3010-9.

123. Oudiz RJ, Galie N, Olschewski H, et al. Long-term ambrisentan therapy for the treatment of pulmonary arterial hypertension. J Am Coll Cardiol 2009;54:1971-81.

124. Zuckerman WA, Leaderer D, Rowan CA, et al. Ambrisentan for pulmonary arterial hypertension due to congenital heart disease. Am J Cardiol 2011; 107:1381-5.

125. McGoon MD, Frost AE, Oudiz RJ, et al. Ambrisentan therapy in patients with pulmonary arterial hypertension who discontinued bosentan or sitaxsentan due to liver function test abnormalities. Chest 2009;135:122-9.

126. Galie N, Ghofrani HA, Torbicki A, et al. Sildenafil citrate therapy for pulmonary arterial hypertension. N Engl J Med 2005;353:2148-57.

127. Chau EM, Fan KY, Chow WH. Effects of chronic sildenafil in patients with Eisenmenger syndrome versus idiopathic pulmonary arterial hypertension. Int J Cardiol 2007;120:301-5.

128. Garg N, Sharma MK, Sinha N. Role of oral sildenafil in severe pulmonary arterial hypertension: clinical efficacy and dose response relationship. Int J Cardiol 2007;120:306-13.

129. Humpl T, Reyes JT, Holtby H, et al. Beneficial effect of oral sildenafil therapy on childhood pulmonary arterial hypertension: twelve-month clinical trial of a single-drug, open-label, pilot study. Circulation 2005; 111:3274-80.

130. Lim ZS, Salmon AP, Vettukattil JJ, et al. Sildenafil therapy for pulmonary arterial hypertension associated with atrial septal defects. Int J Cardiol 2007; 118:178-82.
131. Mikhail GW, Prasad SK, Li W, et al. Clinical and haemodynamic effects of sildenafil in pulmonary hypertension: acute and mid-term effects. Eur Heart J 2004;25:431-6.

132. Mukhopadhyay S, Sharma M, Ramakrishnan S, et al. Phosphodiesterase-5 inhibitor in Eisenmenger syndrome: a preliminary observational study. Circulation 2006;114:1807-10.

133. Singh TP, Rohit M, Grover A, et al. A randomized, placebo-controlled, double-blind, crossover study to evaluate the efficacy of oral sildenafil therapy in severe pulmonary artery hypertension. Am Heart J 2006;151:851 e851-5.

134. Rosenzweig EB, Kerstein D, Barst RJ. Long-term prostacyclin for pulmonary hypertension with associated congenital heart defects. Circulation 1999; 99:1858-65.

135. Fernandes SM, Newburger JW, Lang $P$, et al. Usefulness of epoprostenol therapy in the severely ill adolescent/adult with Eisenmenger physiology. Am J Cardiol 2003;91:632-5.

136. Badesch DB, McLaughlin VV, Delcroix M, et al. Prostanoid therapy for pulmonary arterial hypertension. J Am Coll Cardiol 2004;43:56S-61S.

137. Frost AE, Quinones MA, Zoghbi WA, et al. Reversal of pulmonary hypertension and subsequent repair of atrial septal defect after treatment with continuous intravenous epoprostenol. J Heart Lung Transplant 2005;24:501-3.

138. Simonneau G, Barst RJ, Galie N, et al. Continuous subcutaneous infusion of treprostinil, a prostacyclin analogue, in patients with pulmonary arterial hypertension: a double-blind, randomized, placebo-controlled trial. Am J Respir Crit Care Med 2002;165:800-4.

139. Barst RJ, McGoon M, McLaughlin V, et al. Beraprost therapy for pulmonary arterial hypertension. J Am Coll Cardiol 2003;41:2119-25.

140. Galie N, Humbert M, Vachiery JL, et al. Effects of beraprost sodium, an oral prostacyclin analogue, in patients with pulmonary arterial hypertension: a randomized, double-blind, placebo-controlled trial. J Am Coll Cardiol 2002;39:1496-502.

141. Oudiz RJ, Schilz RJ, Barst RJ, et al. Treprostinil, a prostacyclin analogue, in pulmonary arterial hypertension associated with connective tissue disease. Chest 2004;126:420-7.

142. D'Alto M, Romeo E, Argiento P, et al. Bosentan-sildenafil association in patients with congenital heart disease-related pulmonary arterial hypertension and Eisenmenger physiology. Int J Cardiol 2012; 155(3):378-82.

143. Hoeper MM, Markevych I, Spiekerkoetter E, et al. Goal-oriented treatment and combination therapy for pulmonary arterial hypertension. Eur Respir J 2005;26:858-63.

144. Lunze K, Gilbert N, Mebus S, et al. First experience with an oral combination therapy using bosentan 
and sildenafil for pulmonary arterial hypertension. Eur J Clin Invest 2006;36(Suppl 3):32-8.

145. McLaughlin VV, Oudiz RJ, Frost A, et al. Randomized study of adding inhaled iloprost to existing bosentan in pulmonary arterial hypertension. Am J Respir Crit Care Med 2006;174:1257-63.

146. Okyay K, Cemri M, Boyac B, et al. Use of long-term combined therapy with inhaled iloprost and oral sildenafil in an adult patient with eisenmenger syndrome. Cardiol Rev 2005;13:312-4.

147. Benza RL, Miller DP, Gomberg-Maitland M, et al. Predicting survival in pulmonary arterial hypertension: insights from the Registry to Evaluate Early and Long-Term Pulmonary Arterial Hypertension Disease Management (REVEAL). Circulation 2010;122:164-72.

148. Duffels M, van Loon L, Berger R, et al. Pulmonary arterial hypertension associated with a congenital heart defect: advanced medium-term medical treatment stabilizes clinical condition. Congenit Heart Dis 2007;2:242-9.

149. Dimopoulos K, Inuzuka R, Goletto S, et al. Improved survival among patients with Eisenmenger syndrome receiving advanced therapy for pulmonary arterial hypertension. Circulation 2010;121: 20-5.

150. Trulock EP. Lung transplantation for primary pulmonary hypertension. Clin Chest Med 2001;22:583-93.

151. Stoica SC, McNeil KD, Perreas K, et al. Heart-lung transplantation for Eisenmenger syndrome: early and long-term results. Ann Thorac Surg 2001;72: 1887-91.

152. Waddell TK, Bennett L, Kennedy R, et al. Heartlung or lung transplantation for Eisenmenger syndrome. J Heart Lung Transplant 2002;21:731-7.
153. Klepetko W, Mayer E, Sandoval J, et al. Interventional and surgical modalities of treatment for pulmonary arterial hypertension. J Am Coll Cardiol 2004;43:73S-80S.

154. Dimopoulos K, Diller GP, Koltsida E, et al. Prevalence, predictors, and prognostic value of renal dysfunction in adults with congenital heart disease. Circulation 2008;117:2320-8.

155. Dimopoulos K, Peset A, Gatzoulis MA. Evaluating operability in adults with congenital heart disease and the role of pretreatment with targeted pulmonary arterial hypertension therapy. Int $\mathrm{J}$ Cardiol 2008;129:163-71.

156. Rame JE. Pulmonary hypertension complicating congenital heart disease. Curr Cardiol Rep 2009; 11:314-20.

157. Beghetti M, Galie N, Bonnet D. Can "inoperable" congenital heart defects become operable in patients with pulmonary arterial hypertension? Dream or reality? Congenit Heart Dis 2012;7:3-11.

158. Kidd L, Rose V, Collins G, et al. The hemodynamics in ventricular septal defect in childhood. Am Heart J 1965;70:732-8.

159. Yeager SB, Freed MD, Keane JF, et al. Primary surgical closure of ventricular septal defect in the first year of life: results in 128 infants. J Am Coll Cardiol 1984;3:1269-76.

160. Moller JH, Patton C, Varco RL, et al. Late results (30 to 35 years) after operative closure of isolated ventricular septal defect from 1954 to 1960. Am J Cardiol 1991;68:1491-7.

161. Neutze JM, Ishikawa T, Clarkson PM, et al. Assessment and follow-up of patients with ventricular septal defect and elevated pulmonary vascular resistance. Am J Cardiol 1989;63:327-31. 